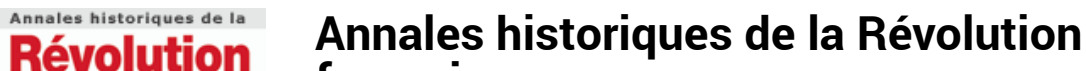

française française

337 | juillet-septembre 2004

Varia

\section{Mémoires de la Terreur : l'an II à Bordeaux}

\section{Philippe Bourdin}

\section{OpenEdition}

\section{Journals}

Édition électronique

URL : https://journals.openedition.org/ahrf/1562

DOI : 10.4000/ahrf.1562

ISSN : 1952-403X

Éditeur :

Armand Colin, Société des études robespierristes

Édition imprimée

Date de publication : 1 septembre 2004

Pagination : 219-221

ISSN : 0003-4436

\section{Référence électronique}

Philippe Bourdin, "Mémoires de la Terreur : I'an II à Bordeaux », Annales historiques de la Révolution française [En ligne], 337 | juillet-septembre 2004, mis en ligne le 15 février 2006, consulté le 23 avril 2022. URL : http://journals.openedition.org/ahrf/1562 ; DOI : https://doi.org/10.4000/ahrf.1562

Ce document a été généré automatiquement le 23 avril 2022.

Tous droits réservés 


\title{
Mémoires de la Terreur : l'an II à Bordeaux
}

\author{
Philippe Bourdin
}

\section{RÉFÉRENCE}

Anne de Mathan, Mémoires de la Terreur : l'an II à Bordeaux, Pessac, Presses Universitaires de Bordeaux, collection « Mémoires vives », 2002, 232 p., ISBN 2-86781-288-7, 24€

1 La collection « Mémoires vives »des Presses universitaires de Bordeaux, qu'il faut féliciter de cette initiative, se propose de publier des manuscrits inédits ou des imprimés oubliés qui deviendront autant de sources accessibles aux historiens. Trois textes, à l'origine regroupés parmi d'autres dans les annexes de la thèse d'Anne de Mathan (Les hommes de la Gironde. Enjeux, acteurs et modalités de l'insurrection de 1793), inaugurent la série : des extraits des Tablettes du prolixe avocat Bernadau (sur la seule période de la Terreur), les Mémoires d'Abraham Furtado et ceux du royaliste Brochon. Soulignons d'emblée la qualité globale de la présentation et notamment les très utiles index qui viennent clore le volume.

2 S'appuyant pour partie sur des manuels de second cycle universitaire - notons l'exclusion des ouvrages d'A. Soboul et de M. Vovelle -, l'introduction d'A. de Mathan renvoie, par ses rappels événementiels, à une histoire convenue des principaux épisodes de la Révolution, qui en néglige le substrat économique et social, voire la construction idéologique - Catherine Duprat a démontré de manière convaincante la part des philanthropes dans nombre des débats de 1789. Les pages sur la Terreur, fondées sur une lecture, parfois critique, des travaux de F. Furet, P. Gueniffey et P. Rosanvallon, veulent « observer comment des dysfonctionnements s'introduisent dans la relation d'un certain nombre de couples dans la machine révolutionnaire, reliant nationalité et citoyenneté, législatif et exécutif, légalité et légitimité, guerre et salut public, et, enfin, idéal et réalité »(p. 18). Ainsi, l'exclusion hors de la nation des privilégiés par Sieyès, transmué pour l'occasion en "démocratique abbé ", lui semble 
l'un des ferments de la suspicion à venir, le « légicentrisme » de 1791 lui paraît devoir favoriser à terme le parti dominant comme la possibilité du veto royal entraîner immanquablement une radicalisation de la vie politique. Les oppositions entre Girondins et Montagnards, le jeu de ces derniers avec la force coactive de la sansculotterie, auraient mérité davantage de nuances, qu'aurait inspirées une bibliographie plus développée (quid, par exemple, du colloque Girondins et Montagnards, des publications de F. Brunel, de R. Monnier, d'H. Burstin ou de M. Biard ?), au lieu de quoi le Comité de salut public devient l'émanation de "foules vociférantes"(p. 24), la Terreur (" chimérique », « délirante », " de la folie »), confondue avec Robespierre et les «robespierristes", est vue comme «le moyen de canaliser l'énergie révolutionnaire »et non « comme une réponse à la famine, ni comme une réponse à la guerre »(pp. 27-29), pour preuve la loi du 22 prairial: la théorie des circonstances relève donc d'une mystification historique construite par les derniers Montagnards... Passons sur la période post-thermidorienne, dont la brève évocation tient davantage des élucubrations des Goncourt.

Nul ne niera les drames indéniables qu'induit la Terreur - et les combats présentement oubliés de la Contre-Révolution -, dont rendent compte le rythme et le nombre des exécutions (les chiffres sont empruntés à D. Greer, R. Sécher et J.-C. Martin), au point que l'auteur, oubliant l'écriture historique, en fait une figure anthropomorphe : «La Terreur couvrit de crêpe funèbre la ville entière ", "La Terreur imprimait tous les sens »(p. 39). A. de Mathan reproduit comme nombre des érudits locaux qui l'ont précédée, les bruits, les odeurs et les couleurs de la mort, associant pêle-mêle cette morbidité aux chants patriotiques, au tutoiement, à l'habit révolutionnaire, aux effets de la déchristianisation. À cause de cette historiographie dépréciative et chancelante, qui ne permet pas d'établir la distance nécessaire du discours aux faits, et néglige nombre des motivations de l'action politique, la description de la situation bordelaise pâtit de ces choix subjectifs et, pour comprendre la présence des représentants en mission dans la capitale girondine, il faut s'en remettre au seul témoignage de la marquise de la Tour du Pin, sans rien savoir de la crise fédéraliste, puis seulement assister à la mise en place des institutions terroristes, à l'arrestation des chefs de la Gironde, prendre acte de la sociologie des suspects - qui mériterait comparaison avec d'autres villes, que les travaux inspirés de la thèse non citée de J.-L. Matharan permettent - et décompter les peines de mort prononcées. Ces perspectives expliquentelles les douze titres sélectionnés en fin de volume, liste dont on saisit mal la logique : dix relèvent de l'histoire locale ou traitent des représentants, auxquels sont amalgamés le dictionnaire Tulard et l'essai de P. Gueniffey sur la Terreur?

4 Sans doute les Mémoires reproduits, corrigés - faut-il s'en réjouir? - des erreurs d'orthographe et de syntaxe, et annotés méritaient-ils mieux que cette entrée en matière ; notons au demeurant qu'ils prouvent combien la répression anti-fédéralistes ne frappa ni tout le monde ni chacun également. Abraham Furtado, membre de la Commission Malesherbes, réunie en 1787 pour discuter du statut des Juifs de France, représente brillamment la communauté juive de Bordeaux, férue des Lumières et de philanthropie, dont il discute au sein de la société du Musée. Engagé dans les municipalités révolutionnaires jusqu'en 1793, fondateur de la Société des Amis de la Constitution, ami de Vergniaud et Gensonné, ce rationaliste participe à la révolte fédéraliste au sein de la Commission populaire de salut public; emprisonné pour ce fait, il profite de ses réseaux religieux et politiques pour se cacher d'abord puis, une fois emprisonné, pour obtenir sa libération au printemps 1794: de là ses Mémoires d'un 
patriote proscrit, presque écrits à chaud. L'avocat Jean-Baptiste Brochon, de dix ans son cadet, membre de la garde nationale et des jacobins, est le fils de Guillaume qui, rebuté par les conséquences de la Constitution civile du clergé, a démissionné de toute fonction élective en 1792 malgré ses primes engagements (municipalité, tribunal civil); Jean-Baptiste, engagé dans les forces fédéralistes (7e bataillon de la force départementale, Société de la Jeunesse bordelaise), comparaîtra deux fois devant la Commisssion militaire avant d'être relaxé grâce au témoignage d'un cafetier jacobin et de servir durant un couple d'années les forces de la République à la frontière espagnole. Ce n'est vraisemblablement qu'en 1815, et non sans confusions (entre la Législative et la Convention) et oubli (son engagement républicain) qu'il porte témoignage de ces épisodes dans L'histoire de mon arrestation et des événements qui me sont arrivés depuis. Son confrère au barreau, Pierre Bernadau, qui a côtoyé les Amis de la Constitution sans aucune fonction publique avant 1793, est le rédacteur des Tablettes polygraphiques, chronique de l'actualité politique, culturelle et scientifique de l'Europe en général et de Bordeaux en particulier, de 1787 à 1852 ; lui aussi participe à la Commission populaire de salut public et met sa section en état d'insurrection, ce qui lui vaudra une arrestation interrompue avec l'aval du représentant Ysabeau.

On se gardera de porter sur ces trois hommes lettrés quelque jugement de valeur que ce soit («Bernadau n'est pas un auteur sympathique», p. 54) pour mieux apprécier leurs témoignages sur le quotidien des bannis de l'an II, la résistance morale des prisonniers, leurs désillusions politiques, les acquis culturels auxquels ils se rattachent - et qui les distinguent de la sans-culotterie - pour mieux supporter leur sort dans les éventuelles antichambres de la mort où ils partagent les derniers instants d'autres condamnés. "Mémoire de la Terreur ", selon le titre de l'excellent livre de Sergio Luzzatto, il y a, et elle est immédiate, intimement ressentie, souvent anecdotique, tant la banalité du quotidien passé peut occuper le temps de l'enfermement, chaque action ou incompréhension devenant révélatrice - il faut savoir gré à A. de Mathan d'avoir en notes infrapaginales démêlé l'écheveau de l'histoire locale. Mais aucun de ces témoignages ne tend seulement au martyrologe ou au procès des représentants en mission ou des jacobins. C'est aussi de la réception de l'actualité parisienne, de l'utilisation de la symbolique, des fêtes révolutionnaires et des cultes décadaires, des contraintes économiques, d'antinomies sociales qu'il est question. À tous ces titres, le matériau proposé aux historiens, qui ne saurait à lui seul rendre compte de «l'an II à Bordeaux », mais en dit long sur les Girondins provinciaux, mérite l'attention. 